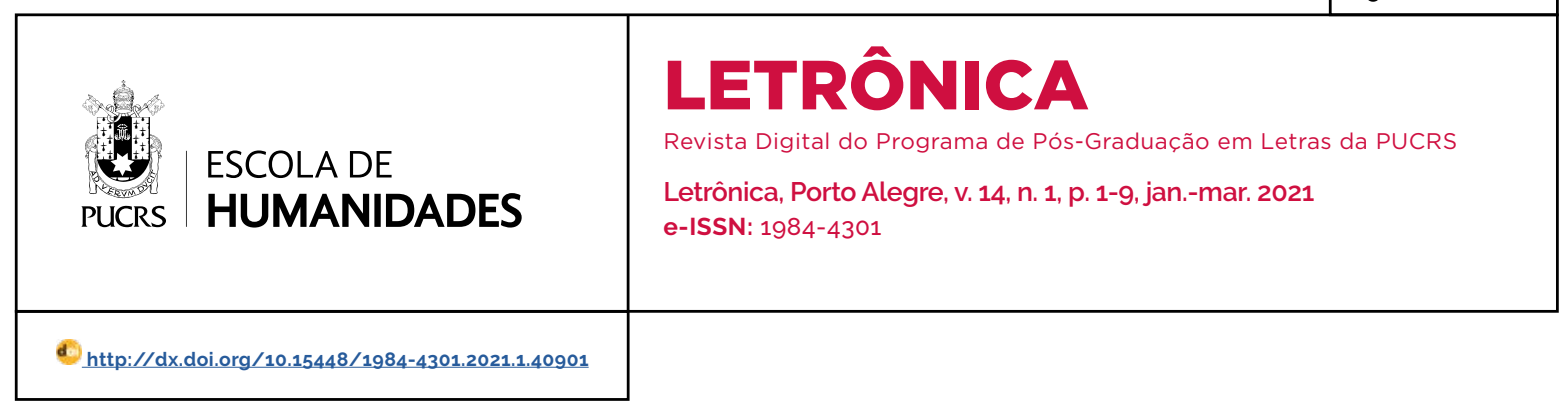

EDITORIAL

\title{
A poesia contemporânea em língua portuguesa ${ }^{1}$
}

\author{
Contemporary poetry in Portuguese language
}

\section{Carlos Alexandre \\ Baumgarten ${ }^{2}$ \\ orcid.org/0000-0001-5760-9114 \\ carlos.baumgarten@pucrs.br}

\section{Alva Martínez Teixeiro 3 \\ orcid.org/0000-0002-8156-7732 \\ alvamteixeiro@campus.ul.pt}

\section{Ívens Matozo Silva ${ }^{2}$}

orcid.org/0000-0002-4100-0811

ivens_matozo@hotmail.com

Recebido em: 5/5/2021

Aprovado em: 6/5/2021

Publicado em: 9/6/2021.

\section{(c) (i)}

Artigo está licenciado sob forma de uma licença Creative Commons Atribuição 4.0 Internacional.

\begin{abstract}
"A poesia é conhecimento, salvação, poder, abandono. Operação capaz de mudar o mundo, a atividade poética é revolucionária por natureza; exercicio espiritual, é um método de libertação interior. A poesia revela este mundo; cria outro".
\end{abstract}

(Octavio Paz, 2012)

Em O arco e a lira, Octavio Paz inicia sua obra com um longo parágrafo, no qual elenca, de forma sumária, um conjunto de conceitos sobre a poesia. Tal conjunto, mesmo sem a pretensão expressa de recuperar a história da reflexão teórica sobre a poesia, contempla uma série de ideias que foram desenvolvidas no curso do tempo e que, transformadas em convenções, orientaram a escrita da poesia. Nesse sentido, podem ser evocados diferentes momentos desse percurso, que cobre, pelo menos, três etapas relevantes para a compreensão da teoria da poesia: a) a da leitura da Poética de Aristóteles realizada pelos neoclássicos, responsáveis pela formulação de uma poética de natureza essencialmente normativa; b) a correspondente à consolidação do Romantismo que, ao promover a abolição do conceito de poesia como imitação, herança dos neoclássicos do Renascimento, afirma a subjetividade do sujeito lírico no seu encontro consigo mesmo e com o mundo; e c) a inaugurada pela lírica moderna e seus desdobramentos no século XX, em que a poesia passa a ser vista como obra do discurso e o sujeito lírico deixa, definitivamente, de ser confundido com a pessoa do poeta.

No âmbito e no percurso antes referidos, situa-se a poesia em Lingua Portuguesa que, como anunciado no dossiê da Letrônica, possui uma antiga e fecunda tradição, cuja origem remonta, pelo menos, à Idade Média: primeiro, com os poetas portugueses; após, já na Era Moderna, com a contribuição de brasileiros e de africanos, ainda que estes últimos não se façam presentes nos ensaios que compõem o presente número da

\footnotetext{
1 O presente texto de apresentação da Letrônica está organizado em duas seções: uma primeira que busca realizar uma brevissima sintese do percurso histórico da poesia portuguesa e da poesia brasileira, ao longo do século XX; uma segunda, que se ocupa da apresentação dos trabalhos que compõem o número da revista. Além disso, apresenta ele uma particularidade: a primeira parte, concebida num registro tipicamente brasileiro do português; a segunda, de dicção essencialmente portuguesa. Tal particularidade é testemunha do trabalho conjunto e frutifero que a área de Letras da PUCRS vem realizando com a Universidade de Lisboa, aqui representada pela professora e pesquisadora Alva Martínez Teixeiro, a quem agradecemos a profunda colaboração.

Pontifícia Universidade Católica do Rio Grande do Sul (PUCRS), Porto Alegre, RS, Brasil.

3 Universidade de Lisboa (UL), Lisboa, Portugal.
} 
revista. Nessa perspectiva, interessa-nos pensar aqui a modernidade e a contemporaneidade da poesia em língua portuguesa, apresentando, em brevíssima sintese, a trajetória do fazer poético em Portugal e no Brasil no curso do século XX.

A modernidade, tal como foi pensada e entendida nas décadas iniciais do século $X X$, manifesta-se em Portugal com a publicação, em 1915, de Orpheu, revista que congregou, entre outros, os poetas Sá-Carneiro, Almada Negreiros, Cortes-Rodrigues e, especialmente, Fernando Pessoa, cuja atuação e influência se prolongará, pelo menos, durante as décadas subsequentes. Na esteira de Orpheu, no ano de 1927, surge Presença, periódico que, além de dar continuidade ao trabalho iniciado pelo grupo de Orpheu, alcançou uma longevidade significativa, uma vez que permaneceu em circulação até o ano de 1940. Em suas páginas, surgem Adolfo Casais Monteiro, Miguel Torga e José Régio, três grandes poetas cujas obras contribuíram decisivamente para a afirmação do chamado Modernismo português. Cleonice Berardinelli, ao analisar a produção poética dos integrantes de Orpheu e Presença, afirma que em ambas as publicações "o poeta voltava-se para si, na contemplação inquisitiva do próprio eu" (BERARDINELLI, 1977, p. 20), sendo essa a marca a unir os dois grupos.

O ano de 1940 é também assinalado pelo aparecimento de um conjunto de publicações sob o título de Novo Cancioneiro, em que a poesia assume uma postura diversa daquela adotada pelos poetas do primeiro Modernismo, uma vez que os integrantes do grupo se debruçam sobre os problemas sociais do país, quando então sua dicção poética revela-se ideologicamente comprometida, a exemplo do que já vinha ocorrendo no plano da narrativa de ficção com os chamados neorrealistas. Destacam-se, nesse sentido, as contribuições de Carlos de Oliveira, Manuel da Fonseca, Mario Dionísio, José Cochofel, entre outros.

Na mesma década de 1940, uma nova publicação sob o título Cadernos de Poesia vem a lume, contemplando três séries: uma primeira, entre os anos de 1940 e 1942; uma segunda, restrita ao ano de 1951; e, por fim, uma terceira, que abarca os anos de 1952 e 1953. Diferentemente dos grupos antecedentes, os poetas presentes nas páginas dos Cadernos de Poesia não constituem, estética e ideologicamente, um grupo unitário, pois os números da publicação contemplam contribuições de autores provenientes de Orpheu, Presença e do chamado Novo Cancioneiro. A despeito disso, a publicação foi responsável pelo lançamento de poetas importantes, como é o caso de Natércia Freire, Sophia de Melo Breyner Andresen e Eugênio de Andrade.

Em meados dos anos 1940, aparece em Portugal um conjunto de poetas surrealistas, entre os quais se destacam Mário Cesariny, Alexandre O'Neil e Antônio Maria Lisboa, cuja influência se fará sentir, com maior ou menor intensidade, na poesia de Sophia de Melo Breyner Andresen, Jorge de Sena, Adolfo Casais Monteiro e, também, na de Luiza Neto Jorge. O Surrealismo em seu sentido estrito não alcançou, contudo, uma maior longevidade em Portugal, à medida que a poesia do País, no curso dos anos 1950 , assumiu novos caminhos, especialmente através do surgimento das seguintes publicações: Árvore, Távola Redonda, Graal e Tempo Presente. O exame do conjunto dessas publicações revela a adoção de dois rumos diversos: se, por um lado, a primeira desenvolve um percurso mais inovador, em que se destacam poetas como Luís Amaro, Raul de Carvalho e Antônio Ramos Rosa, as demais, por outro lado, inserem-se no âmbito de uma perspectiva mais tradicionalista, como se pode constatar na produção poética de Antônio Manuel Couto Viana e de David Mourão-Ferreira.

A década de 1960 abre-se, em Portugal, com uma publicação coletiva em que comparecem cinco novos poetas: Luiza Neto Jorge, Maria Teresa Horta, Gastão Cruz, Casimiro de Brito e Fiama Hasse Pais Brandão. A referida antologia, divulgada no ano 1961, assinala o momento que a crítica e a historiografia literária costumam registrar como a dos poetas da Poesia-61. A poesia do grupo caracteriza-se por assumir um caráter metarreferencial, em que a reflexão sobre o próprio fazer poético vem associada a preocupações de ordem social. Outros poetas associam-se ao grupo, como é o caso de Natália Correia, Rui Belo, Herberto Helder 
e outros que, mesmo havendo iniciado sua carreira anteriormente, integram-se na perspectiva aberta pela Poesia-61. Do mesmo período é a ação levada a cabo por Herberto Helder e Antônio Aragão que publicam, com a participação de autores brasileiros e europeus, Poesia Experimental-1 (1964) e Poesia Experimental-2 (1966).

A partir dos anos 1970, conforme aponta Carlos Reis, observa-se a presença de "uma fluidez geracional que inibe a fixação de movimentos ou de grupos coesos" (REIS, 2005, p. 359) que, entre outros aspectos, é devida à rarefação de publicações e antologias que marcaram o movimento realizado pela poesia portuguesa nas décadas anteriores. Além disso, tal movimento é caracterizado por uma ruptura em relação ao legado modernista e, sobretudo, pessoano, aspectos vistos como inibidores do reconhecimento da variedade e da força da poesia contemporânea portuguesa, objeto de estudo no presente dossiê.

No caso brasileiro, a modernidade está intimamente vinculada ao movimento representado pela Semana de Arte Moderna de São Paulo que, realizada em 1922, assumiu uma natureza diversa daquela anotada em relação à poesia portuguesa, uma vez que o movimento brasileiro se constitui a partir da formação de diversos grupos com orientação estética e ideológica distinta, como se pode observar nas ideias divulgadas pelo grupo do Pau-Brasil, com seu Manifesto da Poesia Pau-Brasil (1924), ou com a Antropofagia liderada por Oswald de Andrade, que lança o Manifesto antropófago (1928) no primeiro número da Revista de Antropofagia, ou ainda, com os intelectuais e escritores vinculados aos movimentos Verde-Amarelo (1924) e Anta (1928). Como afirma Lucia Helena, na fase inicial do movimento, "ao invés de um bloco uniforme, detectam-se várias correntes, até em oposição dentro da 'frente ampla' do Modernismo: dinamistas, primitivistas, nacionalistas, espiritualistas, desvairistas e independentes" (HELENA, 1986, p. 51). Além disso, é importante destacar o surgimento e a publicação de inúmeras revistas no período, que se juntam as já mencionadas: Klaxon (1922), Revista do Brasil (1925), Terra Roxa e Outras Terras (1926), todas em
São Paulo; Estética (1924), Festa (1927), no Rio de Janeiro; A Revista (1925), em Belo Horizonte; Verde (1927), em Cataguases; Arco e Flecha (1928), na Bahia e Madrugada (1929), em Porto Alegre.

Esse primeiro modernismo que se prolonga até o final da década apresenta uma certa unidade. devido à preocupação com o nacional (embora revestida de matizes distintos), à adoção das propostas oriundas das vanguardas europeias das primeiras décadas do século XXe, especialmente, à busca por uma renovação da linguagem poética. Destacam-se, no periodo, as contribuições de Oswald de Andrade, Mário de Andrade, Raul Bopp, Menotti del Picchia e Cassiano Ricardo, dentre muitos outros, que representam os diferentes caminhos trilhados pela poesia modernista até o final dos anos 1920 do século passado.

Contudo, é a partir da década de 1930 que a poesia moderna brasileira atinge a maioridade, através da afirmação de um conjunto de poetas cuja trajetória se estenderá, pelo menos, até meados da década de 1970. É o caso de poetas como Manuel Bandeira que, a despeito de ter estreado antes mesmo da Semana de Arte Moderna, consolida sua produção, em bases definitivamente modernas, com a publicação de Libertinagem (1930), que traz em suas páginas o emblemático "Poética", poema manifesto que consagra definitivamente sua adesão à nova estética. O mesmo ano registra a estreia de Carlos Drummond de Andrade, com a publicação de Alguma poesia (1930), e de Murilo Mendes, com a obra Poemas (1930). Nesse mesmo âmbito, se incluem Vinicius de Moraes, Cecilia Meireles, Jorge de Lima e Mário Quintana que, como os antes referido, promovem a combinação das inovações trazidas pelo primeiro modernismo com o legado poético da lírica ocidental.

Nessa breve sintese que ora se esboça, convém registrar o aparecimento de alguns poetas na metade dos anos 1940, poetas que a crítica e a historiografia literária brasileiras classificam como "geração de 45", na qual incluem a produção de Geir Campos, de Lêdo Ivo, de José Paulo Moreira da Fonseca, de Péricles Eugênio da Silva Ramos e, em alguns casos, a de João Cabral de Melo 
Neto. Embora não constituíssem propriamente um grupo, a poesia dos integrantes da chamada "geração", salvo a exceção de João Cabral, é motivo de inúmeras polêmicas, uma vez que são vistos ora como "neomodernistas", no dizer de Tristão de Ataíde, ora como representantes de um "antimodernismo", nas palavras de Afrânio Coutinho. A crítica mais ácida, contudo, partiu de José Guilherme Merquior que, salvaguardando João Cabral de Melo Neto, diz que na produção dos demais "A poesia pôs gravata. Uma seriedade difusa se espalhou pelo verso. E uma 'construção' de falso ar pensado; como se esses poetas, não tendo chegado a meditativos, ficassem apenas meditabundos. Um passadismo parnasianinho fez a 'rentrée'" (MERQUIOR, 1965, p. 35).

O panorama da poesia brasileira será marcado, a partir das décadas de 1950 e 1960, pela emergência de movimentos de vanguarda, em que se destacam, sobretudo, três: o Concretismo (1956), Poesia Práxis (1961) e o Poema/Processo (1967). O Concretismo, embora tenha como lançamento oficial o ano de 1956, seu grupo fundador constituído por Décio Pignatari, Augusto e Haroldo de Campos, já se reunira, em 1952, em torno da revista Noigandres. Em um mundo que se caracterizava pelo desenvolvimento dos meios de comunicação de massa, em que a imagem e os recursos audiovisuais passavam a dominar a cena cultural, o Concretismo caracteriza-se como uma reação a essa nova circunstância, reação que implicava o redimensionamento da linguagem poética, em que a tomada de consciência do espaço gráfico como agente estrutural da composição se fazia necessária. Dai o isomorfismo, a simultaneidade da comunicação verbal com a não verbal, a desintegração da palavra, que caracterizarão, entre outros elementos, a poesia concretista.

Nascido de uma dissidência entre Mário Chamie e os poetas do grupo Noigandres, no início dos aos 1960, surge uma nova vanguarda, a Poesia Práxis, inicialmente constituída por Chamie e Cassiano Ricardo. A poesia práxis estabelece uma intermediação entre o experimentalismo herdado do Concretismo e a ideia de uma poesia socialmente participativa, na medida em que valoriza o ato de compor, mas não se desvincula da realidade e apresenta inclinações que são de ordem social. Já o Poema/Processo, apesar de ter surgido 11 anos depois do Concretismo, está intimamente vinculado a este último, como se pode depreender da afirmação de Assis Brasil: "o poema processo é uma consequência - não diriamos uma evolução - da poesia concreta que, como vimos, entrou na área dos signos visuais plásticos e à procura de novas experiências" (BRASIL, 1975, p. 121). Destacaram-se no grupo, poetas como Wlademir Dias Pino, Neide de Sá, Álvaro de Sá e Moacy Cirne.

No final da década de 1960, assiste-se a emergência do Tropicalismo que, estabelecendo um diálogo com o movimento antropófago dos anos 1920 e com o Concretismo, inaugura, em certa medida, a poesia brasileira de expressão pós-moderna, ao promover a dessacralização da arte, diluindo a cultura consagrada, misturando o antigo e o novo, o primitivo e o moderno, assumindo, portanto, um caráter sincrético e cosmopolita. A partir do Tropicalismo, a poesia brasileira, como afirmou Carlos Reis em relação à produção portuguesa, não se manifesta mais através de grupos coesos e de publicações de antologias fruto de um trabalho programático, momento em que se fazem sentir, com mais força, as influências características da pós-modernidade.

\section{Do saber poético insular ao conhecimento de arquipélago}

O atual dossiê da revista Letrônica foi concebido pelos seus organizadores como uma essencial e plural aproximação à poesia escrita em língua portuguesa na contemporaneidade. Apesar de que, nele, o esperável era um conjunto de contributos parciais e particulares, os estudos reunidos no atual monográfico, felizmente, ultrapassaram qualquer possivel qualidade insular.

É assim que, ao tecerem uma série de conversas transitivas entre elas e ao criarem diversos harmônicos relacionais, as análises ensaísticas agora reunidas acabaram por edificar um saber de arquipélago e uma estrutura dialogal, em espelho. Em consequência, essa estruturação do saber redimensiona as sugestivas e diversas 
tendências, obras e temas poéticos focados, resultantes do labor de diferentes autores na pluralidade das atuais (e não só) escritas poéticas em português do Brasil e de Portugal.

Um primeiro ensaio de intuitos mais teoréticos do que aplicados, que se situa no âmbito de uma visão panóptica e panorâmica da difícil conceptualização do verso e do ritmo poético, examina a feição não menos conceitual do verso livre a partir do advento da modernidade. Para tal, Júlia Telésforo Osório recorre às origens etimológicas dos vocábulos visados para gerar uma orgânica e iluminadora dissertação ad hoc. Nela, revisitamos significativos e distintos exempla do evoluir do verso-livrismo, nos âmbitos, inter alia, dos "modernismos" - lato sensu - anglo-americano, francês ou português; somos guiados pelas sólidas ideias e inteligentes consideranda de estudiosos-poetas e exímios tradutores, como o brasileiro Paulo Henriques Britto; (re)paramos na análise aplicada do cultivo "verso-liberto", na estrema cadência rítmica do poeta português, radicalmente contemporâneo, Herberto Helder... E todos esses dispositivos argumentativos e disposições expositivas fazem com que Júlia Osório, assumindo o principio gerador do "contínuo desejo de propiciar uma sensação de retorno ao fluxo de um objeto poético", encerre o seu artigo, ressaltando que:

[e]m outras palavras, a escolha artística por versos livres valoriza a liberdade composicional fundamentada na ideia de ritmo associada à de versus, considerados os seus discutidos aspectos etimológicos, em muitas manifestações poéticas produzidas a partir do Romantismo no que tange sua dimensão formal como objeto de arte. ${ }^{4}$

Essa visão geral e teórica, do entrecruzamento do versal e do rítmico, projetado na ponderação da entidade do verso livre para o presente poético, tem uma certa continuidade, em parte e de maneira diferente, no artigo de Cristian Javier Lopez. Entre os polos do genérico e do particular, o autor alicerça o seu estudo na análise de uma dupla musicalidade - "como temática discursiva ou como elemento estruturante da própria poeticidade lírica" -, tanto no ritmo e na sonoridade. quanto nos conteúdos, em dois poemas concretos da singular escritora Helena Kolody: "Música romântica" e "Cantiga". No entanto, como questão derivada dessa análise concreta e de pormenor, Lopez acrescenta à sua dissertação, com não pouca ambição, a intenção reivindicativa de autoras que, como a paranense, produziram e planejaram a sua escrita nas margens sociais e econômicas do País, visando ampliar, nessas coordenadas, a presença da autoria feminina no cânone literário, não só do Brasil, mas também da América Latina no seu conjunto. A abordagem, portanto, examina a relevante musicalidade da poesia kolodyana nas duas maneiras em que surge:

mediante utilização de elementos da linguagem musical, colocados como tema nos poemas; e a partir da musicalidade da palavra em lingua portuguesa, concretizada nas estruturas ritmico-sonoras

Nesse sentido, serve-se de uma produtiva amálgama crítico-teórica, em que ressalta a operatividade analítica do conceito de "massa sonora", gerado e desenvolvido pela muito reflexiva poeta uruguaia Idea Vilariño.

Já o atraente ensaio de Ana Kühn, transita para um aporte mais concreto e específico desse efeito dialógico, acrescentado e enriquecedor, de que antes falamos. Trata-se de uma feliz aproximação a um muito capaz poeta, nos últimos tempos na moda e na ribalta, o brasileiro Paulo Leminski. Nas páginas do texto, revisitamos, por assim dizer, o paideuma de autores e de obras lidos e criticamente assimilados por Leminski, de aqueles que, de maneira influente ou afluente, condicionaram a sua pessoal expressão e a sua apurada autorreflexão - mesmo que, como bem precisa a estudiosa, a perspetiva seja também, e preferentemente, a do viés do poema "Ler pelo não". De fato, não é por acaso que Kühn pretende emblematizar na precisão desses versos leminskianos:

a relação com a tradição que escolheu para si, em especial a concretista, [que] nem sempre é pacífica, mas assinalada por uma tensão, uma vez que essa leitura, por vezes, é realizada pelo viés do não. 
Na verdade, após a leitura do artigo, ficamos mais do que esclarecidos a respeito do diversificado processo leminskiano de leitura e de pensamento critico, mas também da "desleitura, tresleitura e contra leitura" apropriadoras com que Leminski fez que a sua escrita destilasse o alheio em alquimicos parâmetros de excelente poesia.

Noutra linha de sentido, Wilck Camilo Ferreira de Santana e Brenda Carlos de Andrade vão ao encontro da cidade poética do Recife na obra do heterodoxo (e excelente) poeta Joaquim Cardozo, mais um clássico de uma modernidade brasileira que, com a passagem dos tempos, dos modos e das modas, deveu absolutamente contemporânea. Nesse sentido, tendo como firmes alicerces os aportes prévios de Antonio Candido, Beatriz Sarlo, Rodrigo Cantarelli, César Leal ou Eduardo Maia, parte de uma observação, por assim dizer, com lupa da eticidade estetizante presente no extraordinário poema "As janelas, as escadas, as pontes e as estradas", de Mundos paralelos, para alcançar uma outra visão aprofundada da escrita cardoziana. Uma escrita que podemos definir como dialogante e/ou apropriadora relativamente aos seus modelos de partida, como radiográfica a respeito das transformações do moderno urbano, como querendo-se à la page no que faz referência à renovação assentada em uma estética clássica e em uma temática regional com que se implica, tanto no cientificismo de base, quanto na modernidade contemporânea como processo escritural. Na verdade, após esse ponderado levantamento critico, Wilck de Santana e Brenda de Andrade podem concluir com toda a naturalidade e assertividade que, os referidos, entre outros,

[...]são fatores que lançam a poética de Joaquim Cardozo para um espaço de universalidade, podendo, ainda, ser acrescentados fatores como: a concentração de valores poéticos planetários por meio da qualidade, concentração e universalização de imagens; e, sobretudo, o fato de ele enxergar a palavra como o espírito das ações que compõem e criam o mundo.

Nessa mesma linha temática da poetização do urbano (outro), Paulo Sales, servindo-se de significativos exempla paradigmáticos das obras
A cidade e os livros (2002) e Porventura (2012), disserta sobre a importância da paisagem citadina para a fixação dos (neo)contornos dos mundos percebidos e visualizados pelo sujeito lírico despregado pelo (grande) autor fluminense Antonio Cicero. Para tanto, a intencional distorção derivada do entrecruzamento do urbano contemporâneo e da espacialidade acrônica dos mitos, que Cicero convoca e descoloca na escrita, faz com que, para alcançar uma cabal e mais completa compreensão, Sales se debruce com especial cuidado sobre tão relevante questão ad hoc. Desta maneira, assistimos a uma sucinta visão panorâmica urbana, e dos temas citadinos derivados, nos sinuosos trajetos da poesia brasileira ao longo da sua rica história, assim como à enumeração da plêiade de cultores da urbs, especialmente de poetas paulistanos e cariocas, para afinal revistar, em concreto, as muito diversas e complementares estratégias líricas de aproximação anamnésica e pessoal ao "inesgotável" Rio, entre a cidade "irreal" e miseravilhosa. Revisitação que tem como contraponto a aparição e a apropriação conotativa de

[n]omes do universo helênico como Proteu, Ícaro, Dédalo, Fédra, Ájax, Perseu, Medusa e outras tantas personalidades [que] vivem experiências únicas nos entraves com a paisagem urbana contemporânea.

Paulo Sales, após esse reflexivo percorrido, com o filtro basilar de uma "poética da negatividade", afirma com contundência e razão que a poesia ciceroniana em foco:

\begin{abstract}
[...]está sempre em transitoriedade tempo-espacial e é permeada pela mudança. Seus poemas possibilitam contatos do sujeito lírico a paisagens múltiplas que se tornam desterritorializadas pela iminência de encontros entre espaços do presente com os do passado.
\end{abstract}

Por sua vez, o artigo de Constance von Krüger parte da produtiva dialética nietzschiana entre as forças do apolíneo e do dionisiaco e, com ela, elabora uma rentável e sugestiva grelha analítica, dando relevância à tragicidade derivada do dicotômico confronto estabelecido pelo prussiano, poeta e pensador da filologia como arte de bem ler. Grelha conceitual que, em geral, utiliza para a 
análise de vários poemas específicos do itinerário criativo do autor em foco; assim como, em particular, aplica à tensão que percorre os excelentes volumes a cadela sem Logos (2006) e Sons: Arranjo: Garganta (2009), de um dos mais interessantes, complexos e lúcidos poetas contemporâneos brasileiros, Ricardo Domeneck. Esse carnalmente performático e ludicamente corporizado escritor, radicado e também atuante artisticamente nos alternativos espaços berlineses, entrecruza, em produtiva amálgama, desejo - tout court, e não só homoerótico - e razão, escritura e oratura. Em suma, no sentido apontado de uma inegável adequação e aplicabilidade da "arte de bem ler" Domeneck, a ensaísta expõe, muito significativamente, uma relevante ideia-sintese:

[a] ordem do desejo manifestada por meio da sisudez da razão é a pulsão que gera a contradição feliz de que fala Nietzsche - é onde mora o gênio criativo. É nesse espaço de tensão, de estiramento de uma 'cama de gato' (esse vaivém de cordas de símbolos, gestos, efeitos e significados), onde se lê melhor a poesia de Ricardo Domeneck.

Um diálogo intertextual, entre a relevante poesia da atual poeta mineira Ana Martins Marques, autêntica "escritora-apropriadora", e a luminosa escrita da clássica moderna portuguesa Sophia de Mello Breyner Andresen - e no (ab)uso do intertextual a respeito "de tantas e tantos outros poetas" - é o contemplado no muito interessante e não menos sugestivo artigo de Natália Barcelos Natalino. Com uma sólida e plural base teorética à volta da citação - da consabida proposta de Antoine Compagnon e dos argutos críticos Wilberth Salgueiro ou Leonardo Villa-Forte até às reflexões autopoéticas da própria Sophia - ou com a heterodoxia do pensamento alternativo sobre o cosmopolitismo de Abel Barros Baptista, viajamos pelo cânone particular da autora mineira e, ao mesmo tempo, compreendemos melhor a sua criação. Mas também examinamos as naturais e desobrigadas filiações da sua escrita a respeito dos, bref, modos poéticos "modernistas" de aquém e além oceano ou, inter alia, acompanhamos como o texto intitulado "Boa ideia para um poema" consegue brincar com a ideia do roubo poético, da figura do borgeano "plagiário por antecipação", pois, como explicita Natália Natalino:

\begin{abstract}
[o] que, inicialmente, era uma 'Boa ideia para um poema', cai, por fim, num questionamento sobre o próprio fazer poético e sobre a própria rede de conexões e apropriações entretecida nos textos. Por outro lado, evocar o gesto do blefe, da mentira, também não seria colocar Ana vinculada a uma tradição que costuma designar a mulher como aquela que engana, que blefa, plagia, copia?
\end{abstract}

Do intercâmbio basicamente transatlântico empreendido por Natalino, o artigo de Ederval Fernandes transita para uma das duas beiras poéticas antes visadas. É assim que, com base no comentário crítico dos poemas "INão posso adiar o coração para outro século]" e "Poema dum funcionário cansado", de Ramos Rosa, assim como "A invenção do amor" e "[Anjo de fogo]", de Daniel Filipe, o autor analisa com inteligente exatidão tanto como ambos os poetas portugueses, nos conturbados contextos das últimas décadas do regime ditatorial salazarista, vivenciaram a sua compartilhada contemporaneidade, quanto integraram, de maneira abertamente libertária e em diferença, temáticas coincidentes, optando, frente à opressão estético-cultural e sociopolítica, quer pelo doestar da burocracia, quer pela escolha redentorista do amor. Neste sentido, partindo do repetido pensamento agambiano por volta da contemporaneidade entendida, por extenso, nos limites de uma paradoxal temporalidade intempestiva, Ederval Fernandes, considera com razão que, enquanto Daniel Filipe "construiu o seu discurso pelo amor através de um flagrante registro de denúncia", Ramos Rosa "construiu e conduziu a revolução pelo amor para o campo da especulação e criação estético-filosófica". E diz isso, sempre na procura de captar as:

convergências possiveis (modos de ser con-
temporâneos) desses dois poetas portugueses
da segunda metade do século XX diante do
desafio de manterem fixos seus olhares sobre
a época em que viveram.

Uma abordagem mais concreta, regressando à poesia brasileira mais atual e positivamente heterodoxo-marginal, é a realizada por Fernanda 
Boarin, com a sua muito competente leitura relacional da excelente e recente obra poética Seiva, veneno e fruto, da paulistana Júlia de Carvalho Hansen. Essa singular operação interpretativa do poder da palavra poética assenta, por um lado, na aplicabilidade do pensamento derridiano sobre a impronta dos animais, nos espaços fronteiriços da escrita filosófica e/ou poética, e também nos consideranda de Viveiros de Castro, em parâmetros culturais do imaginário "multinatural" ameríndio e do "perspectivismo" amazônico, a respeito do não humano como subjetividade consciente. Ainda, para as ideias do artigo, é igualmente relevante e significativo o substrato do instigante ensaio da própria poeta Ver o que o canto ensina a ver, publicado em 2017, não por acaso, no ano seguinte à aparição do poemário em análise. Nele, o vivenciado e experimentado em um retiro vegetalista ayahuasqueiro é prolongado para a "explicação" do poético e do efeito que ele provoca através da leitura. Não é estranho, portanto, que a partir desse pensum teórico-vivencial, Boarin conclua que, nos poemas dessa impactante obra de Hansen:

quando se escreve o outro, planta ou animal, não estão ali metáforas ou figurações para as quais o sujeito se direciona. Pelo contrário, ao escrever-se através deste jogo relacional, estes signos são lidos como sujeitos, com consciência e intencionalidades, que, trazendo a sua própria voz, transformam a palavra poética em outra, com essa outra lingua não humana, sem deixar de ser quem é.

Os interessantes contributos do dossiê encerram-se com uma resenha critica de inegável interesse. Trata-se de uma avaliação critico-descritiva notoriamente ponderada do instigante ensaio o crepúsculo do contemporâneo da professora portuguesa Paula Cristina Costa. O resenhista, Matheus Rodrigues Gonçalves, procedendo com o cuidado e o rigor exigivel a um complicado gênero, tão avaliativo e criterioso quão sintético e descritivo como é o da recensão crítica, consegue transmitir uma visão convincente do ensaio das ideias-base que a obra enfrenta. O volume com um breve texto prefacial "Só para Coetâneos Contemporâneos nossos", de autoria do professor espanhol Perfecto Cuadrado, anuncia os dois grandes eixos que estruturam e geram o volume: a (re)visão do moderno contemporâneo poético e o aporte de outras artes e modos expressivos. Em primeiro lugar, o da esclarecedora reflexão, no espaço da leitura - especialmente do poético, mas prologando para o campo das artes plásticas -, dos conceitos orteguianos da intimidade do "contemporâneo" e do real "coetâneo". A seguir, Gonçalves explica o como a ensaísta Costa agrega, aos anteriores, os conceitos de tempo e memória com o auxilio do pensum entrecruzado de Rancière, Didi-Huberman ou Badiou - aliás, tão na insistente moda do "imprescindivel" atual. Em segundo lugar, o discurso foca a (in)atualidade do contemporâneo, incorporando as ideias a respeito de Agamben, para continuar visando, em uma visão geral, o acronismo de Cesário Verde, mas também a análise, concreta e ad hoc, do seu excelente poema "Contrariedades"; incorporar o contraste comparativo e paradoxalmente coincidente com Sophia Andresen; convocar outras escritas e ideias do contemporâneo, tout court ou grosso modo, como as de um Bernardo Soares. Gonçalves, enfim, encerra a sua excelente e conotada resenha (por extenso) ratificando a ideia-chave que esteve implícita no seu ancilar discurso descritivo: "um estudo como $O$ crepúsculo do contemporâneo, de Costa, vem para nos munir com as reflexões e teorias necessárias para quando formos buscar reconhecer no céu do dia de hoje, os rastros do crepúsculo de ontem".

E, diga-se também, tais palavras podem ser um bom encerramento desta apresentação e revisitação de um dossiê que, pela qualidade e diversidade dos contributos que acabou reunindo, pode ser visto como mais uma sugestiva antologia de particulares aproximações à poesia contemporânea brasileira e portuguesa, tão excelente quão heterodoxa e diversificada. Ensaios, insistimos, que podem (e devem) ser contemplados como um conjunto em que, reciproca e/ou transitivamente, ecoam saberes entrecruzados que abrem novos e consistentes diálogos criticos por volta das vias das práticas contemporâneas do singularmente plural poético luso-brasileiro. 
Em lógica consequência, só resta explicitar o desejo de compartilhar com os leitores a solidez de um dossiê que só lido poderá devir sólido.

Ergo, votos de uma muito feliz e não menos proveitosa e prazerosa leitura.

\section{Referências}

BERARDINELLI, Cleonice. A poesia portuguesa no século XX. Letras, Curitiba, v. 26, p. 19-35, 1977.

BRASIL, Assis. A nova literatura. Poesia. Rio de Janeiro: Americana, 1975

HELENA, Lucia. Modernismo brasileiro e vanguarda. São Paulo: Ática, 1986

MERQUIOR, José Guilherme. Razão do poema. Ensaios de crítica e de estética. Rio de Janeiro: Civilização Brasileira, 1965.

PAZ, Octavio. O arco e a lira. Tradução de Ari Roitman e Paulina Wacht. São Paulo: Cosac Naify, 2012

REIS, Carlos. História crítica da literatura portuguesa - Do Neo-Realismo ao Post-Modernismo. Lisboa: Editorial Verbo, 2005

\section{Carlos Alexandre Baumgarten}

Doutor e mestre em Linguística e Letras pela Pontificia Universidade Católica do Rio Grande do Sul (PUCRS), em Porto Alegre, RS, Brasil; professor adjunto na Pontifícia Universidade Católica do Rio Grande do Sul (PUCRS), em Porto Alegre, RS, Brasil.

\section{Alva Martínez Teixeiro}

Doutora e mestre em Literatura Brasileira pela Universidade da Corunha (UDC); professora auxiliar de Literatura e Cultura Brasileiras, do Departamento de Literaturas Românicas da Faculdade de Letras da Universidade de Lisboa (FLUL).

\section{Ívens Matozo Silva}

Mestre em Letras pela Universidade Federal de Pelotas (UFPel), em Pelotas, RS, Brasil; doutorando em Teoria da Literatura pela Pontifícia Universidade Católica do Rio Grande do Sul (PUCRS), em Porto Alegre, RS, Brasil. Bolsista CNPq

\section{Endereço para correspondência}

Carlos Alexandre Baumgarten

Pontificia Universidade Católica do Rio Grande do Sul Av. Ipiranga, 6681, Prédio 8

Partenon, 97010-082

Porto Alegre, RS, Brasil

Alva Martínez Teixeiro

Universidade de Lisboa

Alameda da Universidade, 1600-214

Lisboa, Portugal

Ívens Matozo Silva

Pedro Palmeiro, 2200

Lulu Genro, 97700-630

Santiago, RS, Brasil

Os textos deste artigo foram revisados pela Poá Comunicação e submetidos para validação do(s) autor(es) antes da publicação. 